\title{
EL PROGRAMA DE LAS VIRTUDES EN LA IGLESIA DE SAN ISIDORO DE ÚBEDA
}

\section{THE PROGRAM OF VIRTUES IN ÚBEDA'S SAN ISIDORO CHURCH}

\author{
José Miguel Gámez Salas \\ Universidad de Jaén \\ http://orcid.org/0000-000 I-8257-1074
}

\begin{abstract}
This study undertakes an iconographic study of the program of virtues that appears in the nave of the transept of the church of San Isidoro de Úbeda; designed by Alonso Barba in the last third of the 16th century and executed by Sebastián de Solís around 1593. For a proper analysis of the object of this research, I have gathered various literary sources that have allowed me to identify them; they include the ethical-political thought of Antiquity, from Plato to Aristotle, to Seneca or Plutarch; the texts of western Christianity such as the Epistles of Saint Paul; the humanism of Juan Luis Vives and of Erasmus of Rotterdam. Likewise, in this article I indicate the iconographic origin of each of the virtues, some of which arose in Carolingian times, and later received the figurative contributions of French and Italian art.
\end{abstract}

KEYWORDS: Moral Allegory; Virtues; Iconography; Literary Sources; Church of San Isidoro; Úbeda.

RESUMEN • Nuestro trabajo pretende abordar un estudio iconográfico sobre el programa de virtudes que figura en la nave del crucero de la iglesia de San Isidoro de Úbeda; diseñada por Alonso Barba en el último tercio del siglo XVI y culminada por Sebastián de Solís hacia 1593. Para un correcto análisis del objeto de nuestra investigación, hemos recogido diversas fuentes literarias que nos han permitido identificarlas; partiendo del pensamiento éticopolítico de la Antigüedad, desde Platón a Aristóteles, hasta Séneca o Plutarco; los textos del cristianismo occidental mediante las Epistolas de San Pablo; sin olvidar el humanismo de Juan Luis Vives o Erasmo de Rotterdam. Asimismo, en el presente artículo señalaremos el origen iconográfico de cada una de las virtudes, surgidas algunas de ellas en tiempos carolingios, para posteriormente recibir las aportaciones figurativas del arte francés e italiano.

PALABRAS CLAVES: Alegoría Moral; Virtudes; Iconografía; Fuentes literarias; Iglesia de San Isidoro; Úbeda. 


\section{INTRODUCCIÓN}

Tras la conquista cristiana de Úbeda por las tropas de Fernando III el Santo en 1233, se inicia un proceso que consiste en la segmentación de la ciudad en varias collaciones o parroquias. Un total de once fueron fundadas en la ciudad, número que va a permanecer inalterable hasta el siglo XIX. Durante el obispado de don Pedro Pascual (1296-1300), ya se citan estas parroquias en la lista del arciprestazgo de Úbeda perteneciente a la Diócesis de Jaén y que, por orden de dignidad son las siguientes: Santa María, San Pablo, San Pedro, Santo Domingo, Santo Tomás, San Lorenzo, San Juan Evangelista, San Juan Bautista, San Millán, San Nicolás y San Isidoro. De todas ellas, las seis primeras se ubicaban en el interior del perímetro amurallado, mientras que las restantes se diseminaban por sus arrabales (Gámez Salas, 2016: 237; Rodríguez Molina, 1977: 268-273). Es este nuestro caso.

Actualmente la iglesia de San Isidoro ocupa el cuarto lugar como tal, siendo la última en ser construida por Fernando III a mediados del siglo XIII (Ruiz Prieto, 2006: 116). Esta parroquia albergó la demarcación más extensa, quedando completamente nivelada en 1893 en relación al resto, a causa del reajuste parroquial que se inició en la ciudad de Úbeda (Pasquau Guerrero, 1958: 96).

Las dos portadas, denominadas «del Sol»y «de la Luna», corresponden al Gótico tardío y fueron ejecutadas por el cantero Pedro López entre los años de 1510 a 1550 bajo mandato del obispo de la diócesis de Jaén, don Alonso Suárez de la Fuente del Sauce (Almansa Moreno, 2008: 35).

En lo que respecta al crucero de la iglesia, espacio en el que se desarrolla un completísimo programa iconográfico de Virtudes, es obra de Alonso Barba, discípulo del también arquitecto Andrés de Vandelvira, quien planteó como estructura general del templo una réplica de la catedral de Jaén hallando en la nave del transepto un buen paradigma de ello. En él, encontramos un magnífico ejemplo de clasicismo y proporcionalidad, además de la inclusión de una serie de motivos ornamentales manifestados en forma de mascarones que se disponen en las claves de los arcos de medio punto, acompañados de pequeñas canéforas y virtudes reclinadas sobre los mismos que dotan a la nave del crucero de una gran riqueza decorativa alzándose como una extraordinaria alabanza alegórica-moral (Moreno Mendoza, 1985: 165-166).

Sin embargo, pese a ser Alonso Barba el artista encargado de trazar el proyecto constructivo del transepto, este sería culminado por Sebastián de Solís a finales del siglo XVI. Nos consta que el 26 de noviembre de 1592, Solís es nombrado por el obispo don Francisco Sarmiento de Mendoza: «Visitador y Veedor General de Obras» de todo el obispado de Jaén. A partir de este momento, será este quien se encargue no solo de revisar todas las obras alusivas a las diversas construcciones y reformas que se estaban desarrollando en la provincia de Jaén, sino también de culminarlas. Por ello, la tesis de que Sebastián de Solís se responsabilizase de la finalización de la nave del crucero, trazado inicialmente por Alonso Barba, se afianza como una teoría de contundente factibilidad según rezan los documentos de la época (Galera Andreu, 1977: 26).

En cuanto a las Virtudes, estas resultan un tópico icónico en la arquitectura ubetense de la Edad Moderna, identificando su proyección en el palacio de los Torrente, capilla del Camarero Vago (iglesia de San Pablo), sacra capilla de El Salvador, iglesia de San Lorenzo, basílica menor de Santa María, y hospital de Santiago, erigiéndose el crucero de la iglesia de San Isidoro como el espacio que con mayor sublimidad presente un completo programa iconográfico sobre esta tipología figurativa. 
Nos parece preceptivo incluir en el presente exordio, el origen del tema de las virtudes en la arquitectura ubetense, hallando su primera aparición en la fachada del palacio de los Torrente fechada en el primer tercio del siglo XVI, y cuya autoría aún no ha sido descubierta. Estas aparecen en las enjutas del arco de medio punto representadas mediante dos rostros circundados por coronas de laureles en el que figuran las palabras Caritas (en el de la izquierda) y Vertus (a la derecha). Este tipo representativo del tema de las virtudes, en el que se presentan desprovistas de cualquier atributo que pueda identificarlas, volvemos a encontrarlo en la capilla funeraria del Camarero Vago, ubicada en la nave de la epístola de la iglesia de San Pablo, acompañado de un discurso escatológico a través de la inclusión en su portada de numerosas calaveras.

Sin embargo, será en la portada principal de la sacra capilla de El Salvador, diseñada por el ilustre artista del renacimiento español Diego de Siloé entre los años de 1536-1540, donde podamos visualizar la primera representación de virtudes junto a sus correspondientes atributos. No obstante, estos últimos no figuran a causa de su destrucción probablemente durante la Guerra Civil española. A pesar de ello, reconocemos a las virtudes por dos cartelas que se encargan de definirlas: Fe y Justicia. Ya expuesta la ausencia de atributos en ambas, valoramos la más que plausible aparición de la cruz para ilustrar a la Fe, y la espada para hacerlo del mismo modo a la Justicia. La representación de virtudes prosigue en toda la capilla de El Salvador, tanto en su exterior con la portada Meridional realizada por Andrés de Vandelvira entre 1541-1543, en la reja ejecutada por Francisco de Villalpando en 1555, y en la rotonda con la escenificación de las virtudes cardinales pintadas por Antonio de Medina en el último tercio del siglo XVIII (Chueca Goitia, 1971: 109).

Concluida nuestra introducción, procederemos al correspondiente análisis iconográfico de cada una de las virtudes presentes en la nave del crucero de la iglesia de San Isidoro de Úbeda.

\section{LA FE}

La presente alegoría la hallamos formulada en tiempos romanos, no en vano su abstracción conceptual remite a la fe de los soldados en su jefe o bien la del pueblo en su gobernante. Fue Numa quien levantó el primer templo dirigido a la Fe enseñando a los romanos: «a tener el de la Fe por el mayor de todos los juramentos» (Plutarco, 1983: 41). La Antigüedad clásica prestó algunos atributos a esta alegoría, tales como la tórtola, las flores, las espigas, los corazones o el caduceo. Sin embargo, cuando la Fe fue establecida por el cristianismo como un concepto de gran exclusividad por parte de este, los motivos anteriormente mencionados fueron sustituidos por el cáliz, la cruz o el libro sagrado (Agustín, 1744: 43-44).

La alegoría de la Fe del crucero de la iglesia de San Isidoro porta un cáliz y una cruz [fig. 1], aludiendo el primero de ellos a la copa sobre la que se recogió la sangre de Cristo, y el segundo al instrumento con el que fue martirizado conformando las Arma Christi. Ambos ya blasonaban desde el siglo XIII el escudo de la mayestática virtud teologal en las catedrales francesas de París, Chartres y Amiens. También visualizamos dichos atributos en tierras italianas, caso de la portada del Duomo de Como o en el sepulcro del arzobispo Ricci en Pisa. Por lo tanto, en el caso que nos compete, podemos afirmar que nos encontramos ante unos símbolos que son el resultado de una mezcolanza iconográfica del mundo francés e italiano, siendo este último el que procuraría la supervivencia de ambos atributos en los siglos posteriores (Didron Ainé, 1860a: 238). 


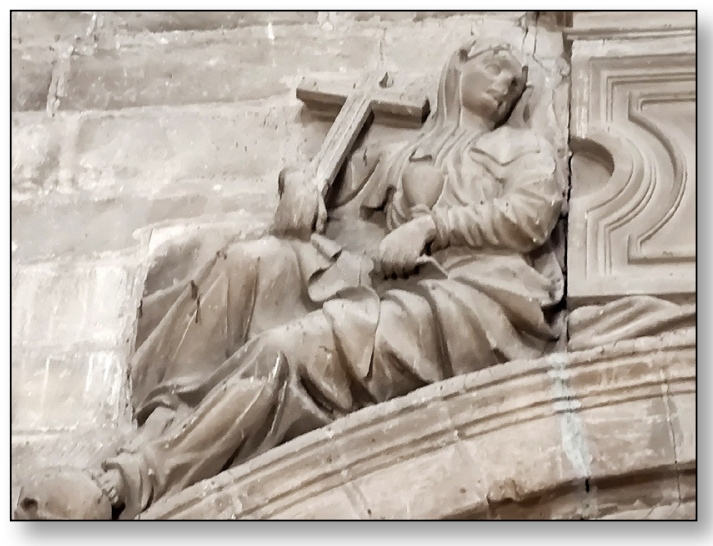

Fig. 1. La Fe.

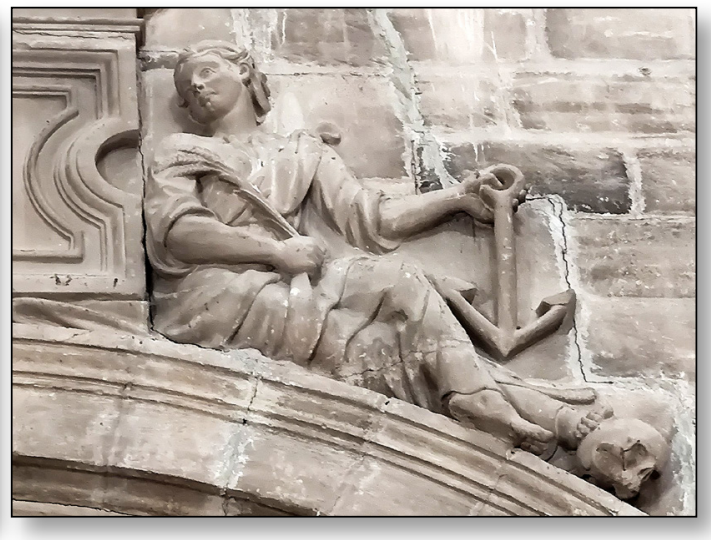

Fig. 2. La Esperanza.

\section{LA ESPERANZA}

Igual que ocurre con la Fe, esta virtud ya fue conceptualizada en el Mundo Antiguo, pues ya Hesíodo (1972: 47) en su poema Los Trabajos y los Días explica que la Esperanza es la única que permaneció encerrada en la vasija que contenía todos los males, y que posteriormente fue destapada por Pandora. Otro poeta griego como Teognis de Megara se refirió a la Esperanza "como la única diosa que habita entre los humanos".

Nuestra imagen porta una palma y un ancla [fig. 2]. Este último atributo podemos encontrarlo en el cristianismo primitivo, apareciendo por vez primera en el cementerio de Priscila asociada a la palabra $\mathcal{\Lambda} \Lambda \mathrm{IIS}$ (Esperanza), símbolo nunca antes reflejado en la iconografía funeraria romana (León Coloma, 1988: 62). Su fuente literaria procede de la Epístola a los Hebreos de San Pablo $(6,19)$ : «tenemos la Esperanza como segura y firme áncora de nuestra alma, y que penetra hasta el interior del velo, adonde entró por nosotros como precursor Jesús».

El ancla marina simboliza la esperanza de la vida y el viento favorable para los tripulantes de un barco, significado que es recogido en un manuscrito de Aristóteles del último cuarto del siglo XV conservado en la Biblioteca de Rouen, mediante una imagen de la Esperanza que porta sobre su cabeza un barco, aludiendo al navegante que aguarda la esperanza de llegar al destino deseado (Didron Ainé, 1860b: 293). Uno de los primeros modelos en suelo español que refleja la iconografía de la Esperanza acompañada por un ancla, es la imagen que esculpiese Gil de Siloe para la tumba de Juan II de Castilla en la Cartuja de Miraflores en Burgos (1493).

Resulta curioso el caso de la virtud de esta iglesia que porta una palma a causa del escaso número de virtudes que presentan dicho atributo debido a la ausencia identificadora que este otorga, o sea, la palma no se refiere a ninguna de las virtudes, ni cardinales o teologales. Sí bien es cierto que ya en la Antigüedad Clásica hallamos varios ejemplos literarios que referencian a ella como símbolo de la victoria y del triunfo a través de la Descripción de Grecia realizada por Pausanias (2000: 48), o del aforismo de las Metamorfosis de Apuleyo (1985: 11) "palmae victricis foliis», incluso también el Antiguo Testamento da testimonio de ello: "el justo prosperará como la palmera» (Sal. 92, 13). Hablamos pues, de que este atributo evocaría un carácter virtuoso, interpretación que sí está relacionada con la doncella que personifica la Esperanza, estableciendo así una lógica en la dialéctica iconográfica de esta virtud. 


\section{LA CARIDAD}

Está representada por una bella matrona que amamanta a unos niños [fig. 3]. Dicha tipología -seguimos a Guy de Tervarent- se remonta a la Edad Media. No obstante, ya se encontraba reflejada en monedas romanas asociada al concepto de Piedad o Fecundidad, siendo el Ara Pacis un buen ejemplo de ello, concretamente a través de la imagen de la diosa Tellus, otro argumento para poder afirmar la existencia de este tipo iconográfico desde la época romana. Por lo tanto, nos encontramos ante una que ha sobrevivido con el discurrir del tiempo, perviviendo en mundos completamente opuestos (Tervarent, 2002: 184).

Las representaciones de la Caridad amamantando a unos niños fueron muy usuales en Italia, albergando un nexo de unión con la imagen del pelícano alimentando con su propia sangre a sus polluelos y que se encuentra presente en los ya citados manuscritos de la Biblioteca de Rouen. Asimismo, esta imagen traduce el amor al prójimo que junto con el amor a Dios significa a la Caridad como virtud, según una definición que será tópica en la literatura religiosa (León Coloma, 1990: 314).

\section{LA PENITENCIA}

De especial singularidad es la inclusión de la figura de María Magdalena en un programa iconográfico de virtudes, más allá, tal y como planteamos a continuación, que esta represente a la virtud de la Penitencia. La santa, a causa de su condición pecaminosa, se marchó al desierto a vivir una vida eremítica y ascética con el fin de redimir tal estigmatización.

Vinculada al concepto de metánoia, proceso que consiste en la conversión al cristianismo, ya aparece invocado en el Evangelio de Marcos al exponer (Mc. 1-4): "Apareció Juan el Bautista en el desierto, proclamando un bautismo de conversión para el perdón de los pecados" (Morales, 1983: 206). No obstante, sería Tertuliano quien naturalizaría los conceptos de converti y conversio, manifestados en los Hechos de los Apóstoles (Hc. XV, 3) cuando se refieren a la conversión de los gentiles.

Para Plotino, quien transformará el mito platónico sobre el descenso de las almas, sustituye el término de metánoia por el de epístrofe profundizando en una penitencia iniciada desde el corazón: «Vuélvete al Señor desde el fondo de tu corazón y ruégale confiadamente [...]». Asimismo, se lee una descripción más completa de la Penitencia en el texto latino de Ausonio Galo "Sum Dea, cui nomem nec Cicero ipsi dedit. Sum dea, quae facti non factique exigo poenas, Nempe ut poeniteat; sic Metanoea vocor" [Soy la diosa a la que ni siquiera el mismo Cicerón dio nombre./ Soy la diosa que reclama castigo y no hecho/ de modo que sienta arrepentimiento; así soy llamada Metanoia] (Ripa, 1996: 193).

La imagen que aparece en la iglesia de San Isidoro porta como atributos un crucifijo y el tarro de ungüento [fig. 4]; dos de los símbolos que acompañan tradicionalmente a la Magdalena. En cuanto a la cruz, esta presenta sobre ella un Cristo crucificado, mientras que el segundo atributo responde al episodio bíblico en el que la santa ungió los pies a Jesús (Lc. 7, 36-50). El objeto de mostrar el arrepentimiento de María Magdalena basado en el rechazo al vicio y, por ende, en la escenificación de una actitud virtuosa, guarda relación con el repertorio de virtudes que figuran en la iglesia de San Isidoro, instándonos a determinar la inclusión de este personaje bíblico como una forma de representar a la virtud de la Penitencia, la cual, no se encuentra incluida en el septenario clásico de virtudes.

IMAGO, NúM. |3, 202 |, 37-5 | 




Fig. 3. La Caridad.

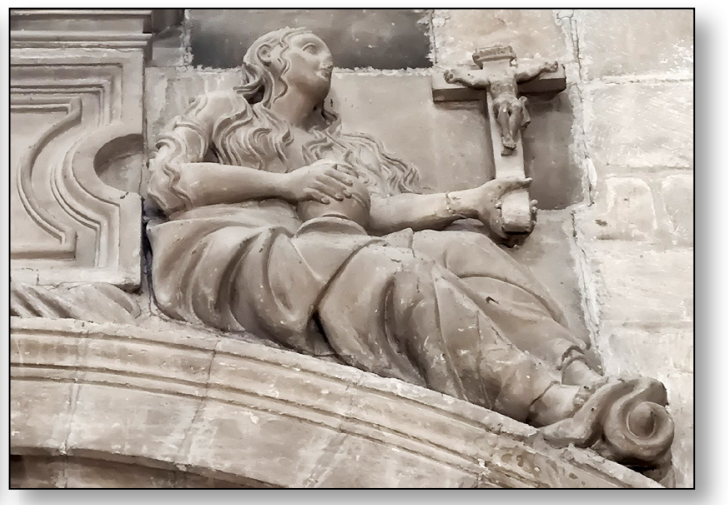

Fig. 4. La Penitencia o María Magdalena.

De esta forma, lo expuesto en el párrafo anterior constituye una hipótesis del por qué la figura de la Magdalena se encuentra integrada en el programa iconográfico de la nave del transepto, subyaciendo en la misma una humilde propuesta que logre conferirnos una sólida justificación a su inserción en la iconografía del crucero.

\section{LA JUSTICIA}

La doncella que personifica esta virtud en la iglesia de San Isidoro de Úbeda porta una espada [fig. 5]. Identificamos este atributo por su empuñadura debido a que el resto de la misma está fracturada. La Justicia se asoció sistemáticamente a la diosa Temis, una de las esposas de Zeus a la que se le atribuye la invención de los oráculos, los ritos religiosos y las leyes. Incluso Píndaro hace de la Justicia la hija de Temis, otorgándole como hermana a la Concordia y como compañera de crianza a la Paz (Píndaro, 1984: 1).

Aristóteles (1973: 1371) expondrá que «La rectitud o justicia es la virtud del alma que se manifiesta en la distribución de las cosas según el mérito propio de cada uno». La literatura romana a través de Cicerón (1997: 299-300) enriquecerá esta alegoría hermanándola con la Fidelidad y encumbrándola como la más excelente de las virtudes, justificando su origen como un estado mental que preserva los intereses de la comunidad garantizando a cada uno lo que merece. Asimismo, Virgilio la identifica con Astrea, hija de Temis; y Petronio establece a la Justicia como hermana de la Fe y la Concordia (Petronio, 1995: 187).

A pesar de que debamos remitirnos exclusivamente al atributo que acompaña a la virtud de la iglesia ubetense, en este caso la espada, sí debemos señalar que la balanza se erigió como el primer atributo que ilustró a la Justicia, hallando sus primeras visualizaciones en la numismática de época romana. Tervarent (2002: 36) apuntó que su justificación literaria procedería de un antiguo proverbio dórico que calificaba a un hombre de irrefutable parcialidad como «más justo que la balanza». En este mismo sentido, no podemos obviar al libro como uno de los atributos más representativos de la Justicia, apareciendo en una miniatura del De Rebus Sicilis de Pietro da Eboli fechado en los últimos años del siglo XII, constituyendo el gran emblema en el que se sustenta la ley para que la justicia imparta correctamente su juicio (Montesinos Castañeda, 2020: 128). 
Remitiéndonos al atributo que presenta la Justicia del crucero de San Isidoro, la espada era considerada para el mundo romano como un símbolo de la magistratura jurisdiccional haciendo referencia al castigo del culpable y a la protección del inocente. La virtud -debido a su deplorable estado de conservación- no facilita la idea de poder confirmar la ceguera de la misma, teoría que no sería nada descabellada por nuestra parte, ya que los ojos cerrados aluden a la neutralidad exigida en el ejercicio de la Justicia. Esta variante de la venda tiene su origen en una alegoría egipcia que fue transmitida por Plutarco y Diodo Sículo, en la que se mostraba al juez desprovisto de ojos para ilustrar su imparcialidad (Panofsky, 2006: 153). De esta forma, como he argumentado anteriormente, no sería ningún despropósito confirmar tal apariencia en la imagen de la virtud ubetense.

\section{LA FORTALEZA}

Reconocida por Platón como una de las cualidades que debía de poseer la ciudad, fue también enaltecida por Aristóteles (1973: 1371) cuando el estagirita destacó su función frente al temor:

Corresponde al valor a fortaleza el no desmayar ante los temores o peligros de muerte, al conservar la confianza en las alarmas y el ser valiente de cara a los peligros y preferir una muerte bella y el ser causa de una victoria antes que una seguridad humillante vil. Corresponde también a la fortaleza el trabajar, el sobrellevar las penalidades de la vida y el desempeñar en ella la parte que corresponde al hombre. El valor va acompañado de confianza, de valentía, y de audacia y también de perseverancia y paciencia.

Pese a la supervivencia de tales exégesis durante el Medioevo, será Santo Tomás de Aquino (1955-1960: 704) quien dedique todo un tratado a la Fortaleza indicando su funcionalidad y objetivos, además de las partes en que esta se divide:

Es propio de la fortaleza impedir que la voluntad se aparte del bien de la razón por temor de un mal corporal. Es, pues, necesario que la fortaleza del alma sea la que conserve a la voluntad del hombre en el bien racional contra los mayores males, ya que quien resiste a ellos resistirá evidentemente a los menores, pero no viceversa; porque es propio también de la virtud a tener en cuenta y tender a los último.

Visualmente, la Fortaleza ha sido provista a lo largo de los siglos de motivos alusivos al carácter bélico, figurando usualmente mediante la representación de un guerrero. Teodulfo de Orleans identificó en el siglo $\mathrm{X}$ a esta virtud por su armadura y atuendos armamentísticos formados por una daga, escudo y yelmo, hallando tal iconografía en el Sacramentario de Autun o en la Biblia de San Paolo fuori le Mura. En este mismo sentido, el cristianismo también visualizó a la Fortaleza a través de la figura de un guerrero, revelando San Pablo en su Epístola a los Efesios la idiosincrasia moral que debía de mostrar el buen cristiano ante las amenazas del diablo:

Por lo demás, fortaleceos en el Señor y de la fuerza de su poder. Revestíos de las armas de Dios para poder resistir a las acechanzas del Diablo. (...) Por eso, tomad las armas de Dios, para que podáis resistir en el día malo, y después de haber vencido todo, manteneros firmes. ¡En pie!, pues; ceñida vuestra cintura con la Verdad y revestidos de la Justicia como coraza, calzados los pies con el Celo por el Evangelio de la paz, embrazando siempre el escudo de la Fe, para que podáis apagar con él todos los encendidos dardos del Maligno (Ef., 6, 11-18). 
La virtud de la Fortaleza que se encuentra esculpida en la iglesia protagonista de nuestro trabajo porta una columna [fig. 6]. Dicho atributo constituye la forma más habitual de representarla, justificando su presencia por ser la parte más sólida del edificio, argumento expuesto por Didron Ainé (1860c: 41) en su estudio iconográfico sobre las virtudes cardinales. Guy de Tervarent (2002: 106) señala que una posible fuente literaria sea el Apocalipsis 3,12 que recoge la siguiente promesa: «al vencedor yo le haré columna en el templo de mi Dios...".



Fig. 5. La Justicia.

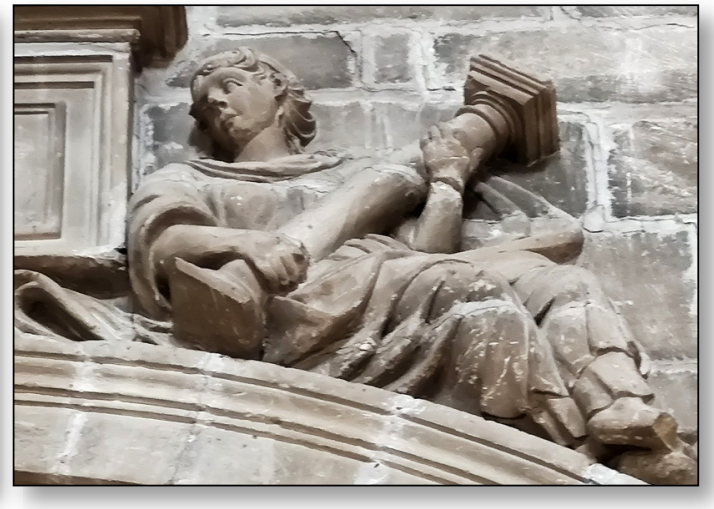

Fig. 6. La Fortaleza.

También es conveniente advertir que los iconógrafos Émile Mâle y Raimond von Marle calificaron a la columna como el símbolo de la fuerza por antonomasia, arguyendo que este atributo recuerda al desplome de las columnas provocado por Sansón sobre los filisteos. ${ }^{1}$ Considero que esta justificación es la más convincente, ya que explicaría de esta forma también la quebradura del fuste de la columna que será representado continuamente para identificar a la virtud de la Fortaleza (Marle, 1971: 67).

El atributo de la columna tiene su origen en el arte italiano, pudiendo hallar diversas reproducciones del mismo desde la Edad Media, estableciendo de esta forma una variante iconográfica para personificar a la Fortaleza, frente a las figuraciones francesas que la proveían de un pequeño torreón del que se arrancaba con violencia un dragón alojado en su interior; tal y como se observa en una de las ilustraciones que presenta el manuscrito de Aristóteles conservado en la Biblioteca de Rouen.

Existe una diferencia notable entre la virtud de la Fortaleza y el resto de virtudes; esta sí mantiene el atuendo militar con las que se las proveyó en la Psychomachia de Prudencio, siendo Mâle (1929a: 151-152) quien planteó la posible justificación de tal iconografía remitiéndose a la -ya invocada en párrafos anteriores- Epístola a los Efesios de San Pablo, quien exhortó al buen cristiano a vestirse como un guerrero.

1. También las columnas acompañan a Hércules para redundar en su fortaleza física, obteniendo especial significancia cuando el dios pagano las separó en el estrecho de Gibraltar. 


\section{LA PRUDENCIA}

«La prudencia es aquella virtud por cuya razón los hombres eligen aquello que es bueno, y evitan aquello que es malo, y aman más los mayores bienes que los menores, y temen más los mayores males que los menores» (Lulio, 1953: 133). Esta exacta definición de Raimundo Lulio en su Filosofía moral constituye una clarividente visión de la concepción sobre esta virtud que se manifestaba en la Edad Media y que era heredada de la filosofía antigua y de la ética aristotélica. Para Aristóteles (1995a: 205) «el hombre prudente es aquel que es capaz de deliberar y juzgar de una manera conveniente sobre las cosas que pueden ser buenas y útiles para él». La definición del filósofo griego está influenciada del intelectualismo socrático, y consecuentemente platónico, por ello, eleva a la prudencia a la categoría de virtud dianoética o intelectual (Aristóteles, 1995b: 67). Las reflexiones sobre la Prudencia que vertieron diversos escritos de la Antigüedad Clásica traspasaron los preceptos de la filosofía antigua hasta incluso mantenerse en la teología cristiana, la cual, erigió a la Prudencia al rango de virtud cardinal (León Coloma, 1989: 65). De la Prudencia se distinguen otras virtudes que las componen, hallando su origen literario, nuevamente, en la filosofía aristotélica cuando el estagirita distinguió hasta cuatro elementos que la conforman: Memoria, Experiencia, Perspicacia y Deliberación (Aristóteles, 1931d: 257). ${ }^{2}$

La filosofía estoica expresó su singular definición de la Prudencia a través de Séneca proveyéndola de tres componentes; Memoria, para recordar el pasado, Inteligencia, permitiéndonos ordenar el presente, y la Providencia, imprescindible para contemplar el futuro. Será esta última la más elogiada por el filósofo romano al aducir la siguiente sentencia: "Más bien previene las cosas que infunden temor, prevé cuando la Prudencia puede prever, observa y aleja de ti, mucho antes de que suceda, todo cuanto pueda perjudicarte» (Séneca, 1884: 434). No obstante, la Providencia como elemento inalienable de la Prudencia no será únicamente recogida por la literatura de Séneca, identificando similar argumento en los Fastos de Ovidio (2017: 7) cuando enaltece al dios Jano por su virtualidad fisionómica basada en la bifrontalidad, ${ }^{3}$ permitiéndole observar el Oriente y el Poniente, así como el presente y el futuro. De esta forma, una de las representaciones más antiguas de la Prudencia consistirá en mostrar el rostro bifronte de Jano en diversas monedas romanas, como aquella de Septimio Severo que se conserva en el Museo Nacional de Arte Romano en Mérida.

Remitiéndonos a la virtud de la Prudencia del crucero de la iglesia de San Isidoro, esta porta una serpiente en su mano izquierda [fig. 7], atributo que encuentra su justificación literaria en el Evangelio de Mateo: «sed prudentes como serpientes» (Mt 10,16); y ya desde el siglo XIII será este reptil el que blasone el escudo de la Prudencia en las catedrales de París y Chartres (Mâle, 1919a: 149). La idea de personificar a esta virtud bajo el símbolo de la serpiente no promueve el ejercicio de la misma, ni tampoco lo obstruye, recogiéndose su virtuosismo en la Historia de los animales de Claudio Eliano (1984: 16).

Por otra parte, en la mano derecha se observa la destrucción parcial de un objeto cuya base evoca a la de un espejo, símbolo perfectamente justificable para acompañar a la Prudencia. Su figuración alude al autoconocimiento, concretamente a la materialización objetual del Nosce te ipusm sustentada por la filosofía socrática, cuyo origen debemos localizarlo

2. Para un conocimiento más profundo de las virtudes que componen a la Prudencia (Montesinos Castañeda, 2019: 199-216).

3. La definición de bifrontalidad como símbolo de la Prudencia será introducida en el cristianismo por los Saturnales de Macrobio, quien le otorgará absoluta exclusividad como aspecto figurativo de esta virtud.

IMAGO, NÚM. I3, 2021, 37-5 | 
en Italia al ser ya presentado como atributo de la Prudencia en las pinturas que Giotto realizase para la capilla paduana de los Scrovegni, obra de irrefutable prestigio al introducir novedosas aportaciones iconográficas respecto a la visualización de las virtudes; y de igual forma reconocemos al espejo como símbolo de la Prudencia en el manuscrito aristotélico conservado en la Biblioteca francesa de Rouen.

Una prueba del grado de aceptación que obtuvo la iconografía de esta virtud representada por la bifrontalidad y el espejo, se escenifica en la tumba que el escultor francés Michel Colombe realizase entre los años de 1499-1507 para Francisco II, duque de Bretaña, y su esposa Margarita de Foix, ${ }^{4}$ establecida en la catedral de San Pedro y San Pablo de Nantes (Hourihane, 2012: 177). De esta forma, el presente tipo figurativo de la Prudencia, surgido en el arte italiano, penetraría años más tarde en Francia dando testimonio de su universalización iconográfica.

Asimismo, el compendio iconológico de Ripa justifica la presencia de ambos motivos, al esgrimir que la sierpe yergue su cabeza cuando se ve combativa oponiendo todas las fuerzas de su cuerpo al ataque que recibe y envolviéndose en sus anillos; definiendo al espejo como el mejor instrumento para la cognición de uno mismo al conferirnos el don de regular las acciones si obtenemos el debido conocimiento de nuestros propios defectos (Ripa, 1996: 233).

\section{LA TEMPLANZA}

Aristóteles (1995b: 219) concretó la definición platónica sobre sophrosyne, genéricamente extendida al control de los placeres y apetitos de toda índole. La ética griega y la filosofía moral latina contribuirán a la conformación idiosincrática teológica y literaria del adoctrinamiento cristiano. De este modo, las doncellas descritas por Prudencio en el siglo IV son hijas de un secular legado literario sobre ética, política o teología que se remontan a Platón y a Aristóteles, para más tarde nutrirse de las aportaciones de Cicerón, Séneca, Macrobio, Ambrosio de Milán, Agustín de Hipona, Isidoro de Sevilla o Tomás de Aquino, entre otros (León Coloma, 1998: 214).

Fue Macrobio (1875: 33) quien nos transfirió una temprana sistematización de las virtudes derivadas de la temperantia, a saber: modestia, verecundia, abstinentia, castitas, honestas, moderatio, parcitas, sobrietas y pudicitia, regulación que culmina en el tratamiento enciclopédico que Tomás de Aquino (1955: 422) otorga a la Templanza diseccionándola en sus «partes integrantes»: verecundia y honestas; "partes subjetivas»: abstinentia, sobrietas, castitas y virginitas; y "partes potenciales»: continentia, mansuetudo, clementia y modestia.

El italiano Baltasar de Castiglione (1920: 252-254) definió a la Templanza como la más loable y panegírica virtud que debe mostrar un príncipe, incluso como la única que bastaría para hacer al hombre el ser más afortunado, restituyendo de nuevo la Edad Dorada del reinado de Saturno.

Respecto a la visualización de la Templanza, su más antigua figuración nos retrotrae al arte carolingio del siglo IX portando una antorcha y vertiendo agua en una jarra. Será a partir del siglo XI cuando se universalice la iconografía de la presente virtud rebajando el vino

4. El monumento funerario fue designado al arquitecto francés Jean Perrèal, mientras que el grupo escultórico sí fue realizado por Michel Colombe, quien ejecutó el conjunto junto a su sobrino Guillaume Regnault, su pupilo Jean de Chartres, y el escultor italiano Jérôme de Fiesole (Hourihane, 2012: 177). 
con agua, hallando múltiples ejemplos en el arte del Alto Medioevo francés, alemán e italiano. Este modelo iconográfico fue sustentado por diversos escritos; desde el consejo de San Pablo de no beber el agua sola, sino mezclada con un poco de vino (1 Tm 5, 23); Plutarco (1986: 153-154) ensalzando las propiedades terapéuticas del vino, siempre que sea mezclado con una gran cantidad de agua; hasta la recomendación de beber mitad vino y mitad de agua que Juan Manuel (1952: 267) redactara en El libro de los castigos.

La Templanza dispuesta en la parroquia ubetense presenta una gran complejidad para definir sus atributos debido a un hórrido estado de conservación causado por las innumerables pérdidas y desperfectos que sufrió Úbeda durante la Guerra Civil española; o debido también a que la calidad escultórica, al menos en esta virtud, resulta deficiente en relación al resto de figuras que la acompañan. Sea lo que fuere, el posicionamiento de las manos y la dirección de su mirada no reflejan la prototípica iconografía de la Templanza de mezclar agua con vino [fig. 8].

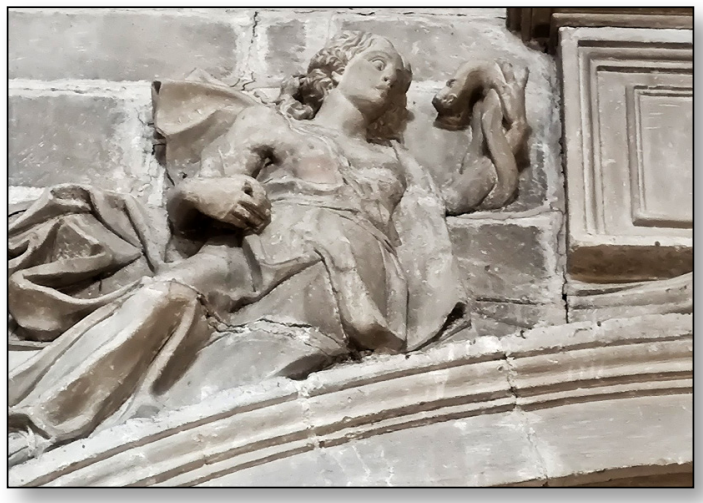

Fig. 7. La Prudencia.

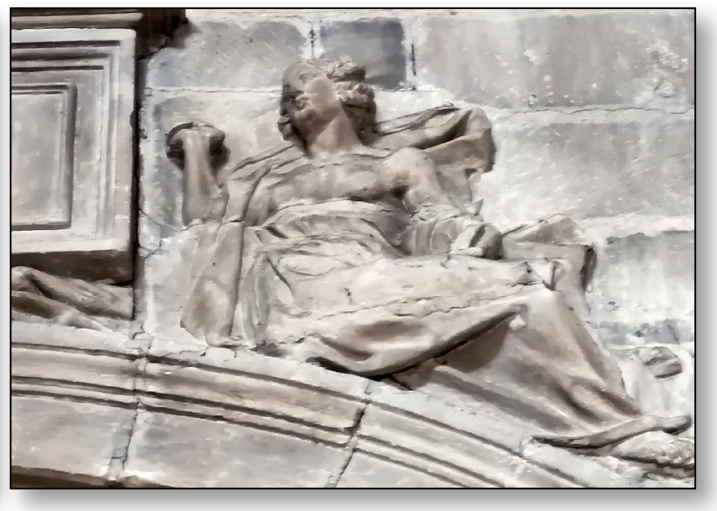

Fig. 8. La Templanza.

Sin embargo, sí podemos inferir a través de la morfología del atributo y del posicionamiento que presenta esta imagen, la posible sustentación de una brida de caballo, desechando otra posibilidad como la opción de que estemos ante la representación de un reloj de arena, motivo que goza de un amplio respaldo literario justificándolo como símbolo de la Templanza; desde las advertencias de la filosofía platónica (Platón, 1988: 315) y estoica (Séneca, 1953: 45), hasta las inquietantes admoniciones del Eclesiastés (2,1-11). A pesar de tal contundente justificación textual, entenderíamos de un gran enrevesamiento plástico la hipótesis de que fuese un reloj de arena el atributo sostenido por la doncella, sobre todo porque en una primera observación, no se identifica tal distintivo, y segundo, en el caso de estar ante una destrucción parcial del mismo, deberíamos distinguir cierto truncamiento en él, que en ningún momento se manifiesta, ni incluso logra atisbarse.

Como hemos redactado en líneas anteriores, sería la brida de caballo el atributo que soporta la virtud de la Templanza del crucero de San Isidoro. Séneca (1984: 165) recomendaba a través de su diálogo Sobre la Ira conducir el espíritu con un freno y una aguijada; y si nos remitimos a la concepción platónica de Templanza como instrumento para atemperar los placeres y apetitos -definición que será más tarde recogida por Agustín de Hipona, Isidoro de Sevilla y Tomás de Aquino- la representación de una brida o freno de caballo está completamente razonada para simbolizar esta virtud (Platón, 2008: 33).

IMAGO, NÚM. 13, 2021, 37-5 I 
Este singular atributo encuentra su origen en el arte carolingio, descrito por Teodulfo de

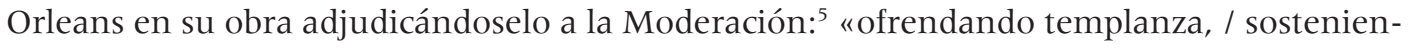
do en su mano fuertes bridas o látigos / con los cuales castiga la indolencia, controla el ímpetu, y con la cual / mantener incluso un rumbo, como si fuera un curso equilibrado" (North, 1979: 199). El humanismo de Juan Luis Vives (1988: 86-87) traduce la gobernabilidad de un pueblo con el de la equitación, comparando «las naciones y pueblos de hombres incitados, encendidos, inflamados y ardientes por todo tipo de vicios, bajeras, vilezas y crímenes con un caballo indomable que rechaza el freno".

Tal adagio de Vives sobre la brida está en connivencia con el aleccionamiento de Erasmo de Rotterdam (1995: 98-99) en el Enquiridión:

Verás hombres que por su carácter tranquilo son tan tratables y dotados que pueden ser educados para la virtud sin dificultad, no necesitando de espuelas para seguir adelante. A otros, por el contrario, les ha tocado en suerte un cuerpo rebelde, casi como decir un caballo desbocado y coceador, de manera que el que lo monta necesita sudar, emplearse a fondo con el freno, la espuela y la fusta para domar su fiereza.

Ya señalado el origen icónico de la brida en el arte carolingio para ilustrar a la Templanza, su figuración se prodigó en tierras italianas como así se atestigua en una de las pinturas de Giotto para la capilla de los Scrovegni, donde se aprecia una brida acompañada por una espada envainada, motivo este último que enfatiza el carácter opositor de esta virtud frente a su correspondiente vicio, la Ira. En una de las Odas de Horacio se puede leer que «ni la guerra civil, ni la violencia romperán la paz / ni la ira que forja las espadas»; y en tal significado Séneca señalaba que "a un hombre encolerizado es mala cosa entregarle una espada" (Gámez Salas, 2017: 136); reconociendo similar exégesis en la obra de Césare Ripa (1996: 335) al calificar a la espada como el principal instrumento de las reacciones violentas «la ira súbito porge la mano al hierro».

La tipología iconográfica de la Templanza representada por una brida de caballo también es recogida en el manuscrito aristotélico de la Biblioteca de Rouen, por lo que dicho atributo debió de convertirse en un motivo frecuente en acompañar a la presente virtud; e idéntico símbolo lo encontramos en la Templanza que Gil de Siloé realizase para la Cartuja de Miraflores en Burgos sobre 1493, convirtiendo a la misma en uno de los primeros referentes iconográficos en el arte español que muestra a la brida como atributo de la Templanza.

\section{CONCLUSIONES}

Finalizado nuestro estudio sobre el programa iconográfico de Virtudes que figura en la nave del transepto de la iglesia de San Isidoro de Úbeda, procedemos a exponer las siguientes deducciones respecto a cada una de ellas.

En cuanto a las virtudes teologales, la Fe acompañada por una cruz y el cáliz debe su origen al arte francés, hallando representaciones de esta virtud con tales motivos en las catedrales de París, Chartres y Amiens. La alegoría de la Caridad mediante una mujer amamantando a dos niños se encuentra endeudada con el concepto romano de piedad, por lo

5. Resulta usual la sustitución de las virtudes por una de las partes que las componen. En el caso de la Templanza será la Moderación la que adquiera tal reconocimiento. 
que su germen iconográfico debemos señalarlo en la Antigüedad Clásica, para ser más tarde recogido por el arte italiano, y no gozando de similar aquiescencia en la plástica francesa. Asimismo, la virtud de la Esperanza con un ancla deviene de un legado multisecular cuya proyección iconográfica ya había sido escenificada en los cementerios paleocristianos como el de Priscila, mientras que el segundo atributo, una palma, resulta infrecuente como motivo de esta alegoría, hallando su significado como símbolo del triunfo en la literatura clásica de Pausanias o Apuleyo, y en la del Antiguo Testamento recogida en el Libro de los Salmos.

La inclusión de la Penitencia dentro de este programa iconográfico resulta singular, al no formar parte del septenario clásico, siendo ilustrada por la figura de María Magdalena para mostrar el rechazo a una vida de pecado y vicio, portando sus dos tradicionales atributos, crucifijo y tarro de ungüento. No cabe duda de que esta virtud fue incluida para lograr un número par de virtudes debido a lugar que había de ocupar.

Respecto a las virtudes cardinales, la Justicia se encuentra representada por una espada, atributo que ya había sido valorado por los romanos como el instrumento por antonomasia para impartir justicia, mientras que la figuración de esta imagen de llevar una venda o mostrar los ojos cerrados alude a una antigua alegoría egipcia recogida en los textos de Plutarco y Diodo Sículo basada en la representación del juez desprovisto de ojos para mostrar su imparcialidad. La virtud de la Fortaleza ilustrada por una columna con fuste quebrado recibe el influjo iconográfico de los modelos italianos, difiriendo de los franceses que la representaban extrayendo un dragón de una torre, tal y como se presenta en el manuscrito de Aristóteles de la Biblioteca de Rouen.

La Prudencia acompañada de una serpiente y un espejo refleja la tipología iconográfica característica de esta virtud, identificando las primeras figuraciones del reptil en suelo francés, caso de las catedrales de Amiens o Chartres; no así del espejo cuya primera escenificación para ilustrar a la Prudencia lo identificamos en las pinturas de Giotto para la capilla paduana de los Scrovegni en 1306, universalizándose ambos atributos una vez fueron recogidos en la Iconología de Ripa. Finalmente, la Templanza de la iglesia ubetense aparece sosteniendo una brida de caballo, identificando su origen iconográfico en el arte carolingio cuya descripción será reflejada en un poema de Teodulfo de Orleans escrito en el siglo IX, proyectándose en el arte italiano debido a las extraordinarias aportaciones figurativas sobre las virtudes que introdujese Giotto en la capilla de la Arena.

\section{BIBLIOGRAFÍA}

Agustín, A. [1744]. Diálogos de medallas, inscripciones y otras antigüedades, Madrid, Joseph Francisco Martínez Abad.

Almansa Moreno, J. M. [2008]. Guía completa de Úbeda y Baeza, Úbeda, El Olivo.

Aristóteles [1973]. Obras, ed. de Francisco Samaranch, Madrid, Aguilar.

Aristóteles [1995a]. Ética eudemia, ed, de Emilio de Lledo Iñigo y Julio Pallí Bonet, Madrid, Gredos.

Aristóteles. [1995b]. Ética a Nicómaco, ed. de Emilio Lledo Iñigo y Julio Pallí Bonet, Madrid, Gredos.

Castiglione, B. de. [1920]. El Cortesano, ed. de Juan Boscán, Madrid, Ed. Saturnino Calleja S.A. 
Cicerón, M. T. [1986]. Sobre la naturaleza de los Dioses, ed. de Julio Pimentel Álvarez, México, D. F: Universidad Nacional Autónoma de México.

Chueca Goitia, F. [1971]. Andrés de Vandelvira, Arquitecto, Jaén, Instituto de Estudios Giennenses.

Didron Ainé. [1860a]. «Iconographie de la Foi», Annales Archéologiques, T. XX.

Didron Ainé. [1860b]. "Iconographie de l'Espérance», Annales Archéologiques, T. XX.

Didron Ainé. [1860c]. "Iconographie des quatre vertus cardinales», Annales Archéologiques. T. XX.

Eliano, C. [1984]. Historia de los animales, ed. de José Ma Díez-Regañón, Madrid, Gredos.

Rotterdam, E. de. [1995]. Enquiridión. Manual del caballero cristiano, ed. de Pedro Santidrián. Madrid, Biblioteca de Autores Cristianos.

Galera Andreu, P. A. Arquitectura de los siglos XVII y XVIII en Jaén, Granada, Caja General de Ahorros y Monte de Piedad.

Galiano Puy, R. [1984]. "Vida y obra del escultor Sebastián de Solís. Un artista toledano afincado en Jaén», Instituto de Estudios Giennenses, 187, 273-350.

Gámez Salas, J.M. [2016]. "Los conventos de San Nicasio y Santa Clara de Úbeda», en M. Peláez del Rosal (ed), El mundo del Barroco y el Franciscanismo, Asociación de Estudios Franciscanos, Baeza-Priego de Córdoba, 237-256.

Gámez Salas, J.M. [2017]. "La iconografía del pecado en la obra bosquiana», Revista Historias del Orbis Terrarum, Anejos de Estudios Clásicos, Medievales y Renacentistas, 13, 99-161.

Hesíodo [1972]. Los Trabajos y los Días, ed. de Ma Josefa Leclyse y Enrique Palau, Barcelona, Iberia.

Hourihane, C. [2012]. The Grove Encyclopedia of Medieval Art and Architecture, Oxoford, University Press, vol. I.

Juan Manuel [1952]. El libro de los castigos, en Escritores en prosa anteriores al siglo XV, Madrid, Atlas.

Katzenellenbogen, A. [1977]. Allegories of The virtues and vices in medieval art, London, The Warbug Institute.

León Coloma, M.A. [1988]. El programa iconográfico de la Real Chancillería de Granada, Granada, Fundación Rodríguez Acosta.

León Coloma, M.A [1989]. «Iconografía de la Prudencia en España durante los siglos XV y XVI", Cuadernos de Arte de la Universidad de Granada, 20, 65-77.

León Coloma, M.A. [1990]. «Un programa iconográfico de vicios y virtudes en la Catedral de Baeza», Ephialte, 2, 312-316.

León Coloma, M.A. [1998]. "Sobre iconografía de la Templanza», Cuadernos de Arte de la Universidad de Granada, 29, 213-228.

Lucio Apuleyo. [1985]. Metamorfosis, ed. de José Ma Royo, Madrid, Cátedra.

Lulio, R. [1953]. Filosofía moral. Madrid, Atlas.

Macrobio. [1875]. Comentaire du songe de Scipion, ed. de M. Nisard, París, Firmin-Didotfrères.

Mâle, É. [1919]. L'art religieux du XIII siécle en France.Etude sur liconographie du Moyen Age et sur sessources d, inspiration, París, Armand Colin.

Marle, R. Von. [1971]. Iconographie del art profane au Moyen Age et á la Renaissance et la décoration des demeures, New York, Haecker Books.

Martín Nieto, E. [1988]. La Santa Biblia, Madrid, San Pablo.

Montes Bardo, J. [1993]. La Sacra Capilla de El Salvador de Úbeda: Arte, Mentalidad y Culto, Úbeda-Jaén: U.N.E.D. 
Montesinos Castañeda, M. [2019]. "Relaciones visuales entre la Prudencia y las virtudes que lo componen", Ars Longa, 28, 199-216.Montesinos Castañeda, M. [2020]. «Manifestaciones visuales de la ley en la imagen de la Justicia», Eviterna, 8, 123-143.

Montesinos Castañeda, M. [2020]. "Manifestaciones visuales de la ley en la imagen de la Justicia», Eviterna, 8, 123-143.

Morales, J. [1983]. "Conversión y Penitencia», en Jesús Sancho et al... (ed.), Reconciliación y Penitencia: V Simposio Internacional de Teología de la Universidad de Navarra, Servicio de Publicaciones de la Universidad de Navarra, 201-213.

Moreno Mendoza, A. [1985]. Guía Histórico-Artística de la Ciudad de Úbeda, Úbeda, Excmo. Ayuntamiento de Úbeda.

North, H. F. [1979]. From myth to icon: reflections of Greek ethical doctrine in literature and art, Nueva York, Cornell University Press.

Ovidio. [2017]. Fastos, ed. de Edu Robsy, Mallorca, Biblioteca digital abierta.

Panofsky, E. [2006]. Estudios sobre iconología, ed. de Bernardo Fernández, Madrid, Alianza.

Pausanias. [2000]. Descripción de Grecia, ed. de Camino Azcona García, Madrid, Alianza.

Pasquau Guerrero, J. [1958]. Biografía de Úbeda, Úbeda, Excmo. Ayuntamiento de Úbeda.

Petronio Arbitro, C. [1995]. El Satiricón y otros escritos, ed. de Enrique Palau, Barcelona, Iberia.

Píndaro. [1984]. Epinicios, ed. de Pedro Bádenas y Alberto Bernabé, Madrid, Alianza.

Platón. [1988]. Las leyes, ed. de José Manuel Ramos Bolaños, Madrid, Akal.

Platón. [2008]. La República, ed. de Rosa Ma Mariño Sánchez-Elvira et al, Madrid, Akal.

Plutarco. [1986]. Obras morales y de costumbres, ed. de Concepción Morales Otal y José García López, Madrid, Gredos.

Plutarco. [1883]. Vidas paralelas. Ed. de Luis Navarro, Madrid: Biblioteca clásica.

Réau, L. [1996]. Iconografía del arte cristiano, ed. de José $\mathrm{M}^{a}$ Sousa Jiménez, Barcelona, El Serbal.

Ripa, C. [1996]. Iconología, ed. de VV. AA, Madrid, Akal.

Rodríguez Molina, J. [1977]. «El diezmo eclesiástico en el Obispado de Baeza-Jaén (siglos XIII-XVI)», Cuadernos de Historia, 7, 268-273.

Ruiz Prieto, M. [2006]. Historia de Úbeda, Úbeda, Asociación Alfredo Cazabán Laguna.

Séneca [1884]. "No debe confiarse en los bienes exteriores», en Epístolas Morales, ed. de Francisco Navarro y Calvo, Madrid, Biblioteca Clásica.

Séneca. [1953]. «De la tranquilidad del ánimo», en Obras escogidas de filósofos, ed. de Adolfo de Castro, Madrid, Atlas.

Séneca [1984]. «Diálogo sobre la Ira», en Diálogos, ed. de Carmen Codoñer, Madrid, Editora Nacional.

Tervarent, G. de. [2002]. Atributos y símbolos en el arte profano, ed. de José María Sousa Jiménez, Barcelona, El Serbal.

Aquino, T. de. [1955]. Suma Teológica, ed. de Fr. Francisco Barbado Viejo y Fr. Santiago Ramírez, Madrid, La Editorial Católica.

Vives J.L. [1988]. Diálogos, ed. de Juan Francisco Alcina, Barcelona, Planeta.

Yarza Luaces, J. [2007]. La Cartuja de Miraflores: los sepulcros, el retablo y las vidrieras, Madrid, Cuadernos de restauración de Iberdrola. 
